\title{
TURNOVER INTENTION PT. EFRATA RETAILINDO DITINJAU DARI BEBAN KERJA, LINGKUNGAN KERJA DAN KEPUASAN KERJA
}

\author{
Esti Khomaryah ${ }^{1}$, Supawi Pawenang ${ }^{2}$, Sholichul Hadi A.B ${ }^{3}$ \\ Universitas Islam Batik Surakarta ${ }^{1,2,3}$
}

Email korespondensi: khomaryahesti@gmail.com ${ }^{1}$

\begin{abstract}
Turnover is a level of employee exit in a company. Turnover is influenced by factors such as workload, work environment and job satisfaction. This research aims to determine the impact of workload, work environment and job satisfaction on turnover intention. Sampling technique of simple random sampling is used in this research. The data was taken directly using a questionnaire distributed to 88 respondents of PT. Efrata Retailindo Surakarta employees. The method of analysis used in this study is multiple linear regression. The results showed that workload, work environment, and job satisfaction have influence on turnover simultaneously. Workload and work environments have a positive and significant impact on turnover while job satisfaction has negative and significant impact on turnover.
\end{abstract}

Keywords: Workload, Work Environment, Job Satisfaction, Turnover Intention

\section{A. PENDAHULUAN}

Manusia merupakan makhluk sosial. Pada dasarnya, manusia memiliki dorongan untuk berinteraksi satu dengan yang lain dan tidak dapat melepaskan diri dari pengaruh manusia lain. Perkembangan zaman yang semakin modern saat ini menuntut perusahaan bersaing ketat untuk mempertahankan kelangsungan hidupnya. Sumber daya manusia merupakan bagian dari perusahaan yang perlu dikelola dengan efektif dan efisien untuk mengurangi pengeluaran perusahaan.

Salah satu masalah yang berpengaruh dengan karyawan yaitu tingkat turnover yang tinggi. Turnover atau keluar masuknya karyawan pada suatu perusahaan merupakan wujud nyata dari turnover intention. Hal ini dapat menjadi masalah serius bagi perusahaan atau organisasi, khususnya apabila yang keluar adalah karyawan atau tenaga kerja yang mempunyai keahlian, kemampuan, terampil dan berpengalaman atau tenaga kerja yang menduduki posisi vital dalam perusahaan. Keadaan tersebut tentunya dapat mengganggu efektivitas jalannya perusahaan. Menurut data yang diterima dari PT. Efrata, dalam kurun waktu 2 tahun perusahaan mengalami tingkat turnover yang cukup tinggi. Mobley (2011) menyatakan faktorfaktor yang mempengaruhi turnover yaitu beban pekerjaan, lingkungan kerja dan kepuasan terhadap kerja. 
Tabel 1. Data Turnover 2018/2019

\begin{tabular}{|c|l|c|c|c|c|}
\hline \multirow{2}{*}{ No. } & \multirow{2}{*}{ BULAN } & \multicolumn{2}{|c|}{$\mathbf{2 0 1 8}$} & \multicolumn{2}{c|}{ 2019 } \\
\cline { 3 - 6 } & & IN & OUT & IN & OUT \\
\hline 1 & Januari & 46 & 18 & 41 & 16 \\
\hline 2 & Februari & 20 & 10 & 51 & 30 \\
\hline 3 & Maret & 36 & 16 & 43 & 20 \\
\hline 4 & April & 39 & 12 & 33 & 15 \\
\hline 5 & Mei & 108 & 10 & 50 & 16 \\
\hline 6 & Juni & 4 & 57 & 14 & 47 \\
\hline 7 & Juli & 12 & 25 & 46 & 34 \\
\hline 8 & Agustus & 0 & 21 & 9 & 28 \\
\hline 9 & September & 8 & 24 & 40 & 30 \\
\hline 10 & Oktober & 19 & 16 & 26 & 21 \\
\hline 11 & November & 21 & 32 & - & - \\
\hline 12 & Desember & 42 & 19 & - & - \\
\hline & Jumlah & 355 & 260 & 353 & 257 \\
\hline
\end{tabular}

Sumber : Data dari Perusahaan

PT. Efrata Retailindo memiliki karyawan sebanyak: 756 orang. Dari hasil observasi dan data tingkat keluar masuknya karyawan yang diperoleh dari perusahaan, ditemukan bahwa hampir setiap bulannya perusahaan mengalami turnover yang tidak wajar. Pada tahun 2018 tingkat turnover yang terjadi pada PT. Efrata Retailindo sebesar 34,39\%, dan pada tahun 2019 sampai bulan Oktober saja, tingkat turnover sudah mencapai 33,99\%. Ada banyak alasan yang melatarbelakangi karyawan keluar, diantaranya tidak betah bekerja, pindah kerja, beban kerja yang terlalu berat, atasan tidak bisa mengatur pembagian kerja, kondisi lingkungan kerja yang kurang kondusif, dan karyawan tidak mampu mengikuti perkembangan dan merasa kurang puas dengan pekerjaannya.

Wisantyo dan Madiistriyatno (2015) menguraikan turnover intention merupakan tingkat keluar masuk karyawan terjadi ketika karyawan meninggalkan organisasi dan harus digantikan. Intensi turnover mencerminkan keinginan individu untuk meninggalkan organisasi dan mencari alternatif pekerjaan di tempat lain.

Beban kerja adalah kegiatan yang membutuhkan proses mental dan kemampuan yang harus diselesaikan dalam jangka waktu tertentu, baik dalam bentuk fisik ataupun psikis (Riani dan Putra, 2017). Muhammad, Adolfina dan Lumintang (2016) menyatakan bahwa lingkungan kerja merupakan segala sesuatu yang ada disekitar para pekerja yang dapat mempengaruhi dirinya dalam menjalankan tugas-tugas yang dibebankan.

Berdasarkan latar belakang diatas makapeneliti tertarik untuk melakukan penelitian dengan judul "Turnover Intention PT. Efrata Retailindo Ditinjau dari Beban Kerja, Lingkungan Kerja dan Kepuasan Kerja" 


\section{B. TELAAH PUSTAKA}

\section{Turnover Intention}

Turnover intention adalah perilaku individu yang berkeinginan untuk pindah atau keluar dari organisasi maupun perusahaan ini merupakan perilaku yang sulit dicegah. Keinginan untuk pindah (turnover intention) yang akhirnya akan muncul keputusan individu untuk meninggalkan pekerjaannya (Sijabat, 2011). Indikator turnover menurut Halimah, Fathoni dan Minarsih (2016) yaitu: (1) memikirkan untuk keluar; (2) pencarian alternatif pekerjaan; (3) niat untuk keluar.

\section{Beban Kerja}

Salah satu faktor yang mempengaruhi turnover yaitu beban kerja. Beban kerja menurut Tarwaka (2011) adalah suatu kondisi dari pekerjaan dengn uraian tugasnya harus diselesaikan pada batas waktu tertentu. Ada beberapa dampak yang ditimbulkan dari beban kerja, yaitu (1) beban kerja ringan, memiliki dampak pada waktu pengerjaan tidak tepat dan penggunaan waktu kerja kurang efektif; (2) beban kerja sedang, berdampak pada penurunan berat badan, sering mengalami kelelahan; (3) beban kerja berat, berdampak pada stres yang berlebihan dan mengakibatkan pekerjaan tidak selesai sesuai dengan waktu yang ditentukan. Indikator beban kerja menurut Putra (2012), yaitu : (1) target yang harus dicapai; (2) kondisi pekerjaan; (3) penggunaan waktu kerja; (4) standar pekerjaan.

\section{Lingkungan Kerja}

Beban kerja memiliki hubungan yang erat dengan lingkungan kerja. Menurut Rivai (2019), lingkungan kerja adalah keseluruhan alat perkakas dan bahan yang dihadapi, lingkungan sekitarnya dimana seseorang bekerja, metode kerjanya, serta pengaturan kerjanya baik sebagai perseorangan maupun sebagai kelompok. Lingkungan kerja yang tidak memuaskan dapat menurunkan semangat kerja dan akhirnya menurunkan produktifitas kerja pegawai. Menurut Sedarmayanti (2011), indikator yang mempengaruhi lingkungan kerja adalah sebagai berikut: (1) penerangan cahaya; (2) temperature di tempat kerja; (3) kelembaban di tempat kerja; (4) sirkulasi udara di tempat kerja; (5) kebisingan di tempat kerja.

\section{Kepuasan Kerja}

Beban kerja dan lingkungan kerja sangat berkaitan erat dengan kepuasan kerja. Kepuasan kerja merupakan ungkapan-ungkapan rasa menyenangkan atau tidak menyenangkan yang timbul dari diri karyawan dalam memandang pekerjaan. Bagi individu, kepuasan kerja salah satu harapan pribadinya. Bagi perusahaan kepuasan kerja berkaitan dengan produktivitas dan bagi masyarakat kepuasan kerja berkaitan dengan pemuasan kebutuhan (Purnomo, 2010). 
Indikator-indikator yang mempengaruhi kepuasan kerja menurut Robbins (2015), sebagai berikut: (1) pekerjaan itu sendiri; (2) gaji; (3) rekan kerja; (4) promosi.

\section{Penelitian sebelumnya}

Irvianti dan Verina (2015) menganalisis pengaruh stres kerja, beban kerja dan lingkungan kerja terhadap turnover intention karyawan pada PT XL Axiata Tbk Jakarta. Hasil penelitian menunjukkan bahwa variabel $\mathrm{X}_{1}$ (stres kerja), $\mathrm{X}_{2}$ (beban kerja), dan $\mathrm{X}_{3}$ (lingkungan kerja) mempengaruhi variabel Y (turnover intention) secara simultan. Polii (2015) melakukan analisis ketertarikan karyawan terhadap pekerjaan dan lingkungan kerja terhadap kepuasan kerja dan turnover intentions karyawan di Rumah Sakit Siloam Manado. Hasil penelitian menunjukkan bahwa ada pengaruh positif signifikan antara job embeddedness terhadap kepuasan kerja, ada pengaruh positif signifikan antara lingkungan kerja terhadap kepuasan kerja, ada pengaruh positif signifikan antara job embeddedness terhadap turnover intention, ada pengaruh positif signifikan antara lingkungan kerja terhadap turnover intention dan ada pengaruh negatif signifikan antara kepuasan kerja terhadap turnover intention.

Hidayati dan Trisnawati (2016) menguji pengaruh kepuasan kerja dan stres kerja terhadap turnover intention karyawan bagian marketing PT. Wahana Sahabat Utama. Hasil penelitian menunjukkan kepuasan kerja dan stres kerja berpengaruh terhadap tingkat turnover intention karyawan PT. Wahana Sahabat Utama, baik secara parsial maupun simultan.

\section{Kerangka Berpikir}

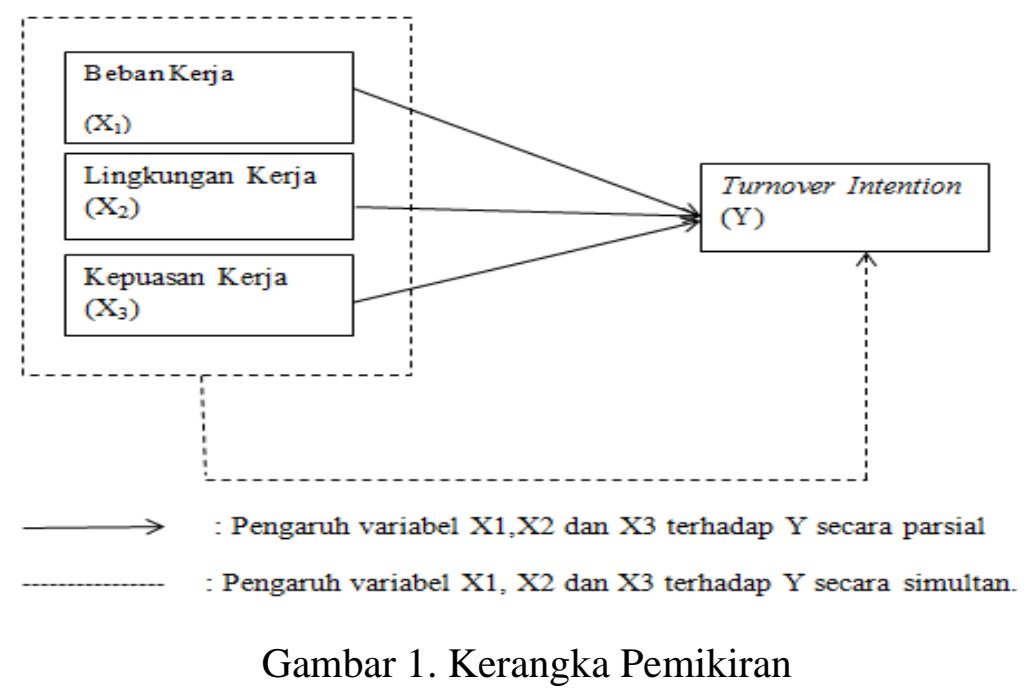

\section{Pengaruh Beban Kerja Terhadap Turnover}

Kondisi pekerjaan, berat atau tidaknya pekerjaan yang ditanggung dapat mengakibatkan turnover intention. Untuk itu, diperlukannya pembagian beban kerja secara adil pada karyawan untuk menekan terjadinya turnover intention pada karyawan. Pada penelitian ini dapat 
disimpulkan apabila beban kerja terlalu tinggi, maka tingkat turnover intention yang terjadi pada karyawan juga akan meningkat. Penelitian ini diperkuat dengan penelitian sebelumnya yang dilakukan oleh Irvianti dan Verina (2015), yang menyatakan beban kerja berpengaruh positif dan signifikan terhadap turnover intention.

$\mathrm{H}_{1}$ : Beban kerja berpengaruh terhadap turnover

\section{Pengaruh Lingkungan Kerja terhadap Turnover}

Semakin baik kondisi lingkungan kerja makan semakin rendah turnover yang dialami oleh suatu perusahaan. Sebaliknya apabila kondisi lingkungan semakin rendah maka intensitas turnover akan tinggi. Untuk itu perusahaan perlu meningkatkan kondisi lingkungan kerja yang aman dan nyaman bagi karyawan. Penelitian ini didukung oleh penelitian sebelumnya yang dilakukan oleh Syaharudin, Utami dan Andini (2017), yang menyatakan bahwa lingkungan kerja berpengaruh positif dan signifikan terhadap turnover intention.

$\mathrm{H}_{2} \quad$ : Lingkungan kerja berpengaruh terhadap turnover

\section{Pengaruh Kepuasan Kerja terhadap Turnover}

Apabila seorang karyawan merasakan kepuasan dalam pekerjaannya, maka ia akan merasa nyaman dengan pekerjaan tersebut. Kepuasan gaji dinilai menjadi prediksi tingkat turnover, karena gaji dirasa paling berpengaruh dibanding dengan indikator kepuasan pekerjan lainnya. Penelitian ini didukung oleh penelitian sebelumnya oleh Polii (2015) dan Waspodo et.al (2013) menghasilkan kesimpulan yang sama bahwa kepuasan kerja berpengaruh negatif dan signifikan terhadap turnover intention.

$\mathrm{H}_{3}$ : Kepuasan kerja berpengaruh terhadap turnover

\section{METODOLOGI PENELITIAN}

\section{Tempat dan Waktu Penelitian}

Penelitian ini dilaksanakan pada PT. Efrata Retailindo kota Surakarta. Waktu pada penelitian ini dilakukan pada bulan September 2019 sampai dengan selesai.

\section{Populasi dan Sampel}

Penelitian yang dilakukan oleh peneliti menggunakan kuesioner dengan 88 responden. Pengukuran dari variabel menggunakan skala Likert. Pada penelitian ini menguji empat variabel beban kerja, lingkungan kerja, kepuasan kerja dan turnover intention. Peneliti menggunakan Random sampling dalam menggambil sampling untuk penelitian yang dilakukan. 
Tabel 2. Definisi Operasional Variabel

\begin{tabular}{|l|l|l|}
\hline \multicolumn{1}{|c|}{$\begin{array}{c}\text { Variabel } \\
\text { Penelitian }\end{array}$} & \multicolumn{1}{|c|}{ Definisi Variabel } & \multicolumn{1}{c|}{ Indikator } \\
\hline $\begin{array}{l}\text { Turnover Intention } \\
\text { Y) }\end{array}$ & $\begin{array}{l}\text { Turnover Intention adalah } \\
\text { kecenderungan atau keinginan } \\
\text { seseorang untuk berpindah dari } \\
\text { satu tempat kerja ke tempat } \\
\text { kerja yang lain. }\end{array}$ & $\begin{array}{l}\text { a. Pikiran untuk keluar } \\
\text { b. Keinginan untuk mencari } \\
\text { pekerjan baru } \\
\text { c. Adanya keinginan untuk } \\
\text { meninggalkan perusahaan } \\
\text { dalam waktu dekat. } \\
\text { (Halimah dkk, 2016) }\end{array}$ \\
\hline Beban Kerja $\left(\mathrm{X}_{1}\right)$ & $\begin{array}{l}\text { Sejumlah kegiatan yang } \\
\text { membutuhkan proses mental } \\
\text { atau kemampuan yang harus } \\
\text { diselesaikan dalam jangka } \\
\text { waktu tertentu, baik dalam } \\
\text { bentuk fisik maupun psikis. }\end{array}$ & $\begin{array}{l}\text { a. Target yang harus dicapai } \\
\text { bondisi pekerjaan } \\
\text { c. Penggunaan waktu kerja } \\
\text { d. Standar pekerjaan } \\
\text { (Putra, 2012) }\end{array}$ \\
\hline $\begin{array}{l}\text { Lingkungan Kerja } \\
\left(\mathrm{X}_{2}\right)\end{array}$ & $\begin{array}{l}\text { Lingkungan kerja adalah } \\
\text { kehidupan sosial, psikologi dan } \\
\text { fisik dalam perusahaan yang } \\
\text { berpengaruh terhadap pekerja } \\
\text { dalam melaksanakan tugasnya. }\end{array}$ & $\begin{array}{l}\text { a. Penerangan cahaya } \\
\text { b. Temperatur tempat kerja } \\
\text { c. Kelembaban tempat kerja } \\
\text { d. Sirkulasi udara } \\
\text { e. Suara bising } \\
\text { (Sedarmayanti, 2011) }\end{array}$ \\
\hline $\begin{array}{l}\text { Kepuasan Kerja } \\
\left(\mathrm{X}_{3}\right)\end{array}$ & $\begin{array}{l}\text { Kepuasan kerja adalah kondisi } \\
\text { psikis yang menyenangkan } \\
\text { yang dirasakan oleh pekerja } \\
\text { atau pegawai di dalam suatu } \\
\text { lingkungan pekerjaan atas } \\
\text { peranannya dalam organisasi } \\
\text { dan kebutuhannya terpenuhi } \\
\text { dengan baik. }\end{array}$ & $\begin{array}{l}\text { a. Pekerjaan itu sendiri } \\
\text { b. Gaji } \\
\text { c. Promosi } \\
\text { d. Rekan kerja } \\
\text { (Robbins, 2015) }\end{array}$ \\
\hline
\end{tabular}

Instrumen Penelitian

Skala pengukuran menggunakan skala Likert untuk menetukan nilaidarisetiapjawaban yangdiperolehdari responden. Peneliti melakukan uji validasi dan reliabilitas dengan menggunakan program SPSS versi 22, program tersebut merupakan program khusus untuk melakukan pengelolaan data statistik.

\section{HASIL DAN PEMBAHASAN}

\section{Pengujian hipotesis}

Penelitian ini sudah melakukan uji asumsi klasik, di antaranya uji normalitas, uji multikolinearitas, dan uji heterokedastistas. Penelitian ini telah lolos uji asumsi klasik. Oleh karena itu, peneliti melakukan pengujian lebih lanjut. 
Table 3. Hasil Pengujian Hipotesis

\begin{tabular}{|c|c|c|c|c|c|c|}
\hline \multirow{2}{*}{\multicolumn{2}{|c|}{ Model }} & \multicolumn{2}{|c|}{$\begin{array}{c}\text { Unstandardized } \\
\text { Coefficients }\end{array}$} & \multirow{2}{*}{$\begin{array}{c}\begin{array}{c}\text { Standardized } \\
\text { Coefficients }\end{array} \\
\text { Beta } \\
\end{array}$} & \multirow[t]{2}{*}{$\mathbf{T}$} & \multirow[t]{2}{*}{ Sig. } \\
\hline & & B & Std. Error & & & \\
\hline \multirow[t]{4}{*}{1} & (Constant) & 9,928 & 2,490 & & 3,987 &, 000 \\
\hline & Beban & 0,256 & 0,086 & 0,272 & 2,971 & 0,004 \\
\hline & Lingkungan & 0,496 & 0,087 & 0,511 & 5,590 & 0,000 \\
\hline & Kepuasan & $-0,137$ & 0,067 & $-0,163$ & $-2,054$ & 0,043 \\
\hline \multirow{3}{*}{\multicolumn{2}{|c|}{$\begin{array}{l}\text { R Square } \\
\text { Adjusted R Square } \\
\text { F value }\end{array}$}} & 0,477 & & & & \\
\hline & & 0,458 & & & & \\
\hline & & 25,497 & Sign. 0,000 & & & \\
\hline
\end{tabular}

Sumber: Data primer diolah

Berdasarkan hasil analisis uji $\mathrm{F}$ diperoleh $\mathrm{F}_{\text {hitung }}$ sebesar 25,497 sedangkan $\mathrm{F}_{\text {tabel }}$ sebesar 2,76. Jadi $F_{\text {hitung }}>F_{\text {tabel, }}$ dengan nilai signifikansi 0,000<0,05 sehingga Ho ditolak. Hal ini berarti ada pengaruh secara simultan antara variabel beban kerja $\left(X_{1}\right)$, lingkungan kerja $\left(X_{2}\right)$ dan kepuasan kerja $\left(\mathrm{X}_{3}\right)$ terhadap turnover intention $(\mathrm{Y})$.

Dari hasil perhitungan diperoleh $t_{\text {hitung }}>t_{\text {tabel }}(2,971>1,992)$ dengan nilai signifikansi $0,004<0,05$ yang artinya Ho ditolak. Hal ini menunjukkan bahwa beban kerja mempunyai pengaruh signifikan terhadap turnover intention.

Dari hasil diperoleh hasil thitung $>t_{\text {tabel }}(5,590>1,992)$ dengan nilai signifikansi $0,000<0,05$ yang artinya Ho ditolak. Hal ini menunjukkan bahwa lingkungan kerja mempunyai pengaruh yang signifikan terhadap turnover intention.

Dari hasil diperoleh hasil $\mathrm{t}_{\text {hitung }}<\mathrm{t}_{\text {tabel }}(-2,054<1,992)$ dengan nilai signifikansi $0,043<0,05$ yang artinya Ho diterima, maka hal ini menunjukkan bahwa kepuasan berpengaruh negatif dan signifikan terhadap turnover inetention.

Dari hasil didapat nilai Adjusted $R$ Square sebesar 0,458. Hal ini berarti menunjukkan bahwa variabel turnover intention dijelaskan oleh variansi variabel beban kerja, lingkungan kerja dan kepuasan sebesar 45,8\%. Sedangkan sisanya sebesar 54,2\% dijelaskan oleh variabel lain yang tidak terdapat dalam penelitian ini, seperti stres kerja, kedisiplinan, kepemimpinan, komunikasi dan sebagainya.

\section{Pembahasan}

\section{Pengaruh Beban Kerja Terhadap Turnover Intention Karyawan PT. Efrata Retailindo}

\section{Kota Surakarta.}

Hasil penelitian menunjukkan terdapat pengaruh positif dan signifikan antara beban kerja terhadap turnover intention karyawan PT. Efrata Retailindo Kota Surakarta. Hal ini 
ditunjukkan dari hasil $\mathrm{T}_{\text {hitung }}>\mathrm{T}_{\text {tabel }}(2,971>1,992)$ dengan nilai signifikansi $0,004<0,05$ yang artinya Ho ditolak. Hal ini menunjukkan bahwa beban kerja mempunyai pengaruh signifikan terhadap turnover intention. Dalam penelitian ini, indikator beban kerja tertinggi didapat pada kondisi pekerjaan. Kondisi pekerjaan, berat atau tidaknya pekerjaan yang ditanggung dapat mengakibatkan turnover intention. Untuk itu, diperlukannya pembagian beban kerja secara adil pada karyawan untuk menekan terjadinya turnover intention pada karyawan. Pada penelitian ini dapat disimpulkan apabila beban kerja terlalu tinggi, maka tingkat turnover intention yang terjadi pada karyawan juga akan meningkat. Penelitian ini diperkuat dengan penelitian sebelumnya yang dilakukan oleh Irvanti dan Verina (2015), yang menyatakan beban kerja berpengaruh positif dan signifikan terhadap turnover intention.

\section{Pengaruh Lingkungan Kerja Terhadap Turnover Intention Karyawan PT. Efrata Retailindo Kota Surakarta.}

Hasil penelitian menunjukkan terdapat pengaruh positif dan signifikan antara lingkungan kerja terhadap turnover intention karyawan PT. Efrata Retailindo Kota Surakarta. Hal ini ditunjukkan dari hasil hasil $\mathrm{T}_{\text {hitung }}>\mathrm{T}_{\text {tabel }}(5,590>1,992)$ dengan nilai signifikansi $0,000<0,05$ yang artinya Ho ditolak. Hal ini menunjukkan bahwa lingkungan kerja mempunyai pengaruh yang signifikan terhadap turnover intention. Lingkungan kerja PT. Efrata yang bagus tidak menjamin rendahnya tingkat turnover karyawan, keinginan meninggalkan perusahaan tidak hanya didasari dari tekanan yang dirasakan ataupun kesediaan seseorang menaati semua peraturan perusahaan. Namun, hal ini juga disebakan tingginya tingkat persaingan, karyawan yang kurang pengalaman mengalami kesulitan beradaptasi dengan job description tambahan, kurang adanya promosi bagi karyawan dan manajemen yang buruk. Penelitian ini didukung oleh penelitian sebelumnya yang dilakukan Syaharudin, Utami dan Andini (2017), yang menyatakan bahwa lingkungan kerja berpengaruh positif dan signifikan terhadap turnover intention.

\section{Pengaruh Kepuasan Kerja Terhadap Turnover Intention Karyawan PT. Efrata Retailindo Kota Surakarta.}

Hasil penelitian menunjukkan bahwa kepuasan kerja berpengaruh negatif dan signifikan terhadap turnover intention karyawan PT. Efrata Retailindo Kota Surakarta. Hal ini ditunjukkan dengan hasil $\mathrm{t}_{\text {hitung }}<\mathrm{t}_{\text {tabel }}(-2,054<1,992)$ dengan nilai signifikansi $0,043<0,05$ yang artinya Ho diterima. Hal ini menunjukkan bahwa kepuasan berpengaruh negatif dan signifikan terhadap turnover intention. Kepuasan kerja merupakan faktor terpenting dalam menekan turnover intention karyawan. Realitanya apabila seorang karyawan merasakan kepuasan dalam 
pekerjaannya, maka ia akan merasa nyaman dengan pekerjaan tersebut. Penelitian ini menunjukkan apabila nilai kepuasan kerja tinggi, maka keinginan karyawan meninggalkan pekerjannya semakin rendah. Peningkatan kepuasan kerja diharapkan mampu menurunkan intensi turnover pada karyawan PT. Efrata. Penelitian ini didukung oleh penelitian sebelumnya yang dilakukan Polii (2015), Mahdi (2012), Findik et.al. (2013), Rizwan (2014) serta Waspodo et.al (2013) juga menghasilkan kesimpulan yang sama bahwa kepuasan kerja berpengaruh negatif dan signifikan terhadap turnover intention.

\section{E. KESIMPULAN}

Dari hasil penelitian dan analisa pada penelitian dapat ditarik kesimpulan sebagai berikut:

1. Variabel beban kerja $\left(X_{1}\right)$, lingkungan kerja $\left(X_{2}\right)$ dan kepuasan kerja $\left(X_{3}\right)$ secara simultan berpengaruh signifikan terhadap turnover intention karyawan PT. Efrata Retailindo Kota Surkarta. Hal ini ditunjukkan dengan nilai $F_{\text {hitung }}>F_{t a b e l}$, maka hipotesis pertama dapat diterima. Dengan demikian, apabila kepuasan kerja pada PT. Efrata Retailindo rendah, maka akan terjadi peningkatan terhadap turnover intention.

2. Beban kerja secara parsial berpengaruh positif dan signifikan terhadap turnover intention karyawan PT. Efrata Retailindo Kota Surakarta. Apabila beban kerja yang diberikan perusahaan terhadap karyawan meningkat, maka tingkat turnover intention juga akan meningkat.

3. Lingkungan kerja secara parsial berpengaruh positif dan signifikan terhadap turnover intention karyawan PT. Efrata Retailindo Kota Surakarta. Artinya semakin tinggi lingkugan kerja, maka semakin tinggi turnover intention karyawan PT. Efrata Retailindo Kota Surakarta.

4. Kepuasan kerja secara parsial berpengaruh negatif dan signifikan terhadap turnover intention karyawan PT. Efrata Reatilindo Kota Surakarta. Jadi, apabila semakin tinggi tingkat kepuasan pada karyawan, mka semakin rendah tingkat turnover intention-nya.

\section{Saran}

Berdasarkan uraian kesimpulan hasil penelitian diatas, peneliti dapat memberi saran sebagai berikut :

1. Bagi peneliti selanjutnya, dapat mengembangkan penelitian dengan meneliti faktor lain yang dapat mempengaruhi turnover intention. Peneliti selanjutnya dapat menganalisis faktor lain seperti stres kerja, motivasi, komitmen organisasi, loyalitas karyawan yang 
memberikan kontribusi agar tingkat turnover intention karyawan menjadi rendah pada suatu perusahaan.

2. Karyawan merupakan aset penting yang dimiliki oleh perusahaan. Oleh karena itu, hendaknya perusahaan memberikan beban atau tanggung jawab kerja pada karyawan sesuai dengan kemampuan, porsi atau standar yang telah ditentukan dan tidak berlebihan, agar karyawan tidak merasa terbebani.

3. Perlunya upaya peningkatan lingkungan kerja dengan menciptakan suasana kerja yang nyaman, kerjasama yang solid, pemeliharaan kondisi fisik kantor yang kondusif dan meningkatkan komunikasi baik dengan rekan kerja maupun dengan pihak lain di luar perusahaan.

4. Peningkatan kepuasan kerja pada karyawan dapat menanggulangi tingkat turnover pada karyawan. Untuk menurunkan tingkat turnover pada karyawan, hendaknya perusahaan meningkatkan kepuasan-kepuasan lain pada karyawan. Hal tersebut dapat dilakukan misalnya dengan cara memberikan jaminan kesehatan pada karyawan, jaminan keselamatan kerja atau dengan bentuk kepuasan lainnya.

\section{DAFTAR PUSTAKA}

Findik, Mehtap, Ogut, A., \& Cagliyan, V. (2013). An Evaluation About Person Organization Fit, Job Satisfaction And Turnover Intention : A Case Of Health Institution. Mediterranean Journal Of Social Sciences, 4, 434-440.

Halimah, T. N., Fathoni, A., \& Minarsih, M. M. (2016). Pengaruh Job Insecurity, Kepuasan Kerja Dan Lingkungan Kerja Terhadap Turnover Intention Pramuniaga Di Gelael Supermarket (Studi Kasus Pada Gelael Superindo Kota Semarang). Journal Of Management, 2.

Hidayati, N., \& Trisnawati, D. (2016). Pengaruh Kepuasan Kerja Dan Stres Kerja Terhadap Turnover Intentions Karyawan Bag. Marketing PT. Wahana Sahabat Utama. Eksis, IX.

Irvianti, L. S., \& Verina, R. E. (2015). Analisis Pengaruh Stres Kerja, Beban Kerja Dan Lingkungan Kerja Terhadap Turnover Intention Karyawan Pada PT. XL Axiata Tbk Jakarta. Binus Business Review, 6, 117-126.

Mahdi, A. F., Zin, M. Z., Nor, M. M., Sakat, A. A., \& Naim, A. A. (2012). The Relationship Between Job Satisfaction And Turnover Intention.American Journal Of Applied Sciences, 9, 1518-1526.

Mobley, W. (2011). Pergantian Karyawan : Sebab, Akibat Dan Pengendaliannya. Jakarta: PT Pustaka Binamanan Pressindo. 
Muhammad, S. R., Adolfina, \& Lumintang, G. (2016). Pengaruh Lingkungan Kerja, Kompensasi Dan Beban Kerja Terhadap Kinerja Karyawan Pada Dinas Pendapatan Daerah Kota Manado. Jurnal Emba, 4, 045-055.

Polii, L. R. (2015). Analisis Keterikatan Karyawan Terhadap Pekerjaan Dan Lingkungan Kerja Terhadap Kepuasan Kerja Dan Turnover Intentions Karyawan Di Rumah Sakit Siloam Manado. Jurnal Emba, 3, 178-190.

Purnomo, H. (2010). Pengantar Pengendalian Hayati. Yogyakarta: Andi.

Putra, A. S. (2012). Analisis Pengaruh Beban Kerja Terhadap Kinerja Karyawan Divisi Marketing Dan Kredit PT. Wom Finance Cabang Depok. Jurnal Studi Manajemen Indonesia, 12.

Riani, N. T., \& Putra, M. (2017). Pengaruh Stres Kerja, Beban Kerja Dan Lingkungan Kerja Non Fisik Terhadap Turnover Intention Karyawan . E-Jurnal Manajemen Unud, 6, 5970-5998.

Rivai, A. (2019). Pengaruh Stres Kerja Dan Lingkungan Kerja Terhadap Keinginan Perawat Untuk Berhenti Bekerja Di Rumah Sakit Columbia Asia Medan. 12.

Rizwan, M. (2014). Preceding To Employee Satisfaction And Turnover Intention. International Journal Of Human Resource Studies, 4, 87-106.

Robbins, S. (2015). Perilaku Organisasi. Jakarta: Salemba Empat.

Sedarmayanti. (2011). Tata Kerja Dan Produktivitas Kerja: Suatu Dari Aspek Ergonomi Atau Kaitan Antara Manusia Dengan Lingkungan Kerjanya. Bandung: Mandar Maju.

Sijabat, J. (2011). Pengaruh Kepuasan Kerja Terhadap Komitmen Organisasi Dan Keinginan Untuk Pindah. Jurnal Visi, 19.

Syaharudin, M., Utami, W., \& Andini, A. P. (2017). Pengaruh Job Insecurity Dan Lingkungan Kerja Terhadap Turnover Intention Melalui Stres Kerja Sebagai Variabel Intervening Pada Karyawan PT. Wonokoyo Jaya Corporindo Pasuruan. Snaper-Ebis, 312-325.

Tarwaka. (2011). Dasar-Dasar Pengetahuan Ergonomi Dan Aplikasi Di Tempat Kerja. Surakarta: Harapan Press.

Waspodo, A. A., Handayani, N. C., \& Paramita, W. (2013). Pengaruh Kepuasan Kerja Dan Stres Kerja Terhadap Turnover Intention Pada Karyawan PT.Unitex Di Bogor. Jurnla Riset Manajemen Sains Indonesia (JRMSI).

Wisantyo, N. I., \& Madiistriyatno, H. (2015). Pengaruh Stres Kerja, Disiplin Kerja Dan Kepuasan Kerja Terhadap Turnover.Junal Mix, V, 54-69. 